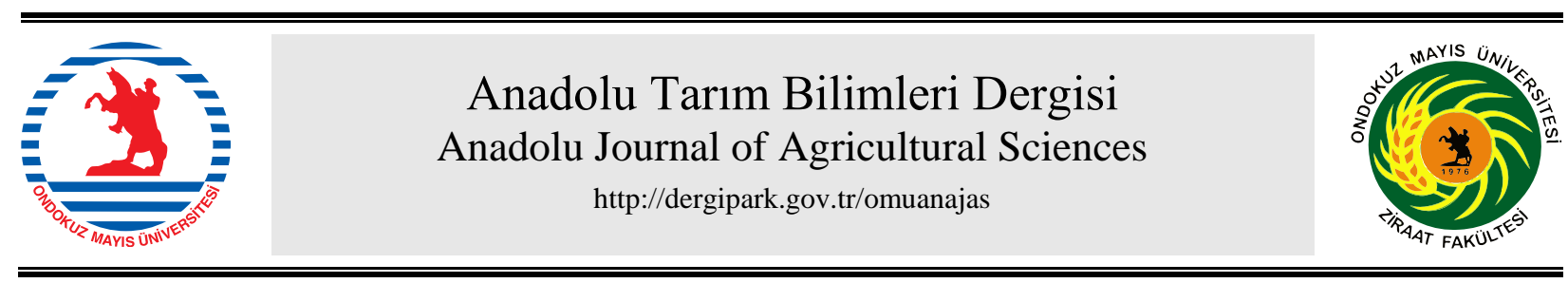

\title{
Araştırma/Research
}

Anadolu Tarım Bilim. Derg./Anadolu J Agr Sci, 33 (2018) ISSN: 1308-8750 (Print) 1308-8769 (Online) doi: 10.7161/omuanajas. 329810

\section{Farklı iki anamateryal üzerinde oluşmuş vertisol toprakların morfolojisi, minerolojik özellikleri ve sinıflaması}

\author{
Fatma Esra Gürsoy*, Orhan Dengiz \\ Ondokuz Mayls Üniversitesi, Ziraat Fakültesi, Toprak Bilimi ve Bitki Besleme Bölümü-SAMSUN \\ *Sorumlu yazar/corresponding author:esra.sarioglu@omu.edu.tr
}

Geliş/Received 20/07/2017 Kabul/Accepted 19/01/2018

\begin{abstract}
ÖZET
Yapılan çalışmanın başlıca amaçları; Samsun ekolojik koşulları altında farklı iki ana materyal (bazalt ve marn) üzerinde oluşmuş dört farlı toprak profilinin morfoloji, mineroloji, fiziksel ve kimyasal özelliklerini belirlemek, ii-) toprakların toprak sınıflamasına göre sınıflamasını yapmak ve iii-) fiziksel özellikler ile minerolojik özellikler arasındaki ilişkilerin incelenmesidir. Çalışma sonucuna göre topraklar alt gurup düzeylerde Calci Haplustert, Entic Haplustert, Chromic Haplustert, Typic Calciustert olarak sınıflandırılmıştır. Toprakların baskın olarak kil minerali simektit grubu 2:1 tipi şişen kil minerallerinden montmorillonit olup, çok az olarakta nontronit ve kaolinit belirlenmiştir.

Fiziksel özelliklerden toprakların likit limit ve plastiklik indeksi değerleri sırasıyla \%53-\%70 ve \%27\%40 arasında değişim göstermektedir. Yüzey horizonlarda likit limit değerleri Calci Haplustert topraklar en yüksek değere sahip iken, Entic Haplustert topraklar ise en yüksek plastiklilik indeks değerine sahip oldukları belirlenmiştir. Birleştirilmiş toprak sınıflama sistemi (USCS)'ne göre ise tüm topraklar yüksek plastisiteli inorganik killer $(\mathrm{CH})$ olarak sınıflandırılmıştır. Aktivite değerlerine göre sınıflandırıldıklarında, aktif olmayan killer sınıfları içerisinde değerlendirilmiştir. İndeks özelliklerine ve aktiviteye bağlı olarak, toprak genişleyebilir killerinin değerlendirilmesi yapıldığında çoğunluğunu genişleyebilen toprakların oluşturduğu görülmektedir. Ayrıca minerolojik testlerin sonuçları, hem indeks özelliklerin sonucu elde edilen değerleri, hem de şişme değerlendirmesi ile elde edilen genişleyebilir toprak özellikleri arasında uyum tespit edilmiştir.

Simektit kil minerallerini fazla düzeyde içeren çalışma alanına ait topraklar, fiziksel ve zemin mühendisliği yönünden elde edilen analiz sonuçları değerlendirildiğinde bu toprakların sorunlu olabileceği söylenebilir.
\end{abstract}

Morphology, minerology properties and classification of vertisols formed on two different parent material

\section{ABSTRACT}

The aims of this study are i-) to determine morphology, mineralogy, chemical and physical properties of four different soil profiles formed on two different parent materials and order, ii-) to classified according to soil taxonomy, and iii-) to investigate between physical characteristic and mineralogical properties. According to this study's results, four soil profiles were classified as Calci Haplustert, Entic Haplustert, Chromic Haplustert, Typic Calciustert and it was determined that montmonilinite which is one of the swellable 2:1 smectite groups was found as dominate clay mineral followed by nontronite and kaolinite. Liquid limit and plastic limit of soils were determined between $53-70 \%$ and $27-40 \%$, respectively. In surface horizon, liquid limit was found the highest value in Calci Haplustert while, Entic Haplustert has the highest plastic limit value. According to USCS classification, all soils were classified as high plasticity, inorganic clay $(\mathrm{CH})$. In addition as classified according to their activity values, they were classified as no active clay. According to index properties and clay mineral all profiles can be said as swellable soils.

According to analysis results, it can be said that studied soils including high amount of swellable smectite clay minerals have problem by taking into consideration of physical ground and soil engineering.
Anahtar Sözcükler:

Kivam limitleri

Kil minerali

Toprak siniflama

Vertisol
Keywords:

Consistence limits

Clay mineral

Soil

ClassificationVertisol 


\section{Giris}

Vertisoller koyu renkli, ağır veya çok ağır bünyeli ve düşük organik madde içeren topraklardır. En önemli özellikleri 2:1 tipi şişebilen smektit grubu kil çeşitlerince zengin olmalarıdır. $\mathrm{Bu}$ nedenle kurak dönemlerde geniş çatlakların oluşmasına, yă̆ışılı dönemlerde şişme aktivitelerinin yüksek olmaları nedeniyle de toprak yüzeylerinde mikro topografya olan "gilgai" lerin oluşmasına neden olmaktadır. Vertisollatince "vertere" alt üst döndürmek anlamına gelmekte olup (Ahmad, 1983), toprak horizonlarının oluşmasını sınırlandırmaktadır. Vertisoller aynı zamanda toprak bilimleri sözlüğünde (SSSA, 1997) $\% 30$ veya daha fazla kil içeren, kuruyken geniş çatlaklara sahip veya gilgai mikro topografya özelliği gösteren, profil içerisinde kama şeklinde ve yatayla yaklaşık 45 derecelik açıyla yerleşmiş strüktürel yapıların bulunduğu topraklar olarak tanımlanmıştır.

Tarım ve mühendislik amaçlı olarak bir toprak profiline ait horizonların değerlendirilmesinde veya profil derinliğinde toprak özelliklerinin değişimini araştırmak amacıyla yapılan çalışmalarda, kıvam limitleri ve şişme-büzülme karakteristikleri gibi mekaniksel özelliklerden faydalanılabilir. Toprak fiziksel özelliklerinin değişiminde etkili olan ve sslanma kuruma süreci içinde ortaya çıkan kabuk oluşumu, çatlama, şişme büzülme, sıkışma gibi, olaylar toprağın mekaniksel özelliklerinin etkisi altındadır (Canpolat ve ark; 1999) . Killi bir toprağa artan miktarlarda su ilave ettikçe önce toprak yumuşayarak plastik bir kıvam almakta su ilavesi devam ettikçe akışkan bir hal almaktadır. Atterberg (1911) bu değişimi tanımlamak için önerdiği metot da toprağın akmaya başladığı andaki nem değerini likit limit (LL), toprağın yarı - katı durumdaki nem değerini ise plastik limit (PL) olarak tanımlamıştır. Likit ve plastik limit olarak tanımlanan metod daha sonra Casagrande $(1934,1958)$ tarafindan geliştirilerek standart uluslararası test olarak kabul edilmiştir. $\mathrm{Bu}$ limitler arasındaki rakamsal fark plastiklik indeksi (Ip) olarak tanımlanmıştır ve ince taneli zeminlerin karakterize edilmesi, sinıflandırılması ve mühendislik özelliklerinin tahmininde çok faydalıdır. Plastiklik killi toprakların en önemli özelliğidir. Killi toprakların her hangi bir mühendislik yapı için kullanımdan önce rutin olarak bakılan bir özelliktir ve diğer tüm mühendislik özelliklerinin iyi bir göstergesidir. Bir toprağın plastisitesini etkileyen faktörlerin onun diğer mühendislik özelliklerini de etkilediği bilinmektedir. Bu bağlamda kil minerallerinin tipinin ve oransal miktarlarının bilinmesi önem taşımaktadır. Killi toprakların mühendislik özellikleri minerolojik bileşimi, özelliklede kil minerolojisi sinıfinın belirtilmesi toprakların fiziksel ve kimyasal özelliklerinin yorumlanmasının yanı sıra toprağın davranışlarının tahminine ve yönetime verdiği tepkinin belirlenmesi için de faydalıdır. Ancak hakim kil minerallerinin davranışı, kil farksiyonunun çeşidi ve oranıyla birlikte düşünülmelidir. Örneğin killi toprakların en önemli özellikleri olan plastiklik, sıkışabilirlik ve şişme potansiyelleri, kil minerali içeriğinin miktarına ve türüne bağlıdır (Grim, 1949; Seed ve ark., 1962; Terzaghi ve Peck; Gillot, 1987). Canbolat ve ark. (1998), Erzurum-Daphan ovas1 topraklarının mekaniksel özellikleri ile pedolojik özellikleri arasındaki ilişkileri belirlemek ve toprağın mekaniksel özelliklerinin tarımsal yönden önemini değerlendirmek amacıyla yürüttükleri araştırmalarında, ova topraklarının yüksek derecede şişme-büzülme zararına sahip olduğu, yüksek plastiklik gösterdiği, mekaniksel kuvvetlere ve suyun gevşeticidispersleştirici etkisine karş1 dirençli olduğunu saptamışlardır. De Jong ve ark. (1990), üç farklı horizondan (A, B ve C) aldıkları toprak örnekleri üzerinde yaptıkları çalışmada, kıvam limitleri üzerine kil içeriği etkisinin $\mathrm{B}$ ve $\mathrm{C}$ horizonunda (ortalama kil içeriği, \%28) A horizonundan (ortalama kil içeriği, \%22) daha fazla olduğunu tespit etmişlerdir. Literatürde toprakların kil boyutu içeriğinin bir fonksiyonu olarak değişen Atterberg limitlerine ilişkin çalı̧̧malara da rastlanmaktadır. Dumbleton ve West (1966) montmorillonit ve kaolonit topraklar ile bunların karışımlarının kil içeriği ile plastikliğini incelemiş ve karşılaştırmışlar, Sivapullahiah ve Sridharan 1985; Tan ve ark., 1994; Nagaraj ve ark 1995; ise çalışmalarında kaolonit, illit, montmorillonit kil minerallerini sirasiyla kum ile karıştırarak sonucunda düşük olmayan kil yüzdeleri için kil boyutu ve Atterberg limitleri arasında doğrusal bir ilişki elde edilmiştir. Bu çalışmada amaç, Vertisol ordosuna ait dört farklı toprağın XRD analizleri sonucu elde edilen kil minerali tipi ve içeriği ile kıvam limitleri arasındaki ilişkiyi ortaya koymaktır.

\section{Materyal ve Yöntem}

Araştırma alanı Orta Karadeniz Bölgesi içerisinde yer alan Samsun ilinde gerçekleştirilmiş olup; Atakum İlçesi yerleşim alanının mücavir alan sınırı içerisinde kalan ve Samsun-Ankara karayoluna cephe olan üzerinde Yeşilkent beldesi, Toybelen, Beypınarı, Kuşçulu ve Çivril köy ve mahallelerinin yer aldığı alan olarak seçilmiştir Çalışma alanı 1:25.000 ölçekli F36a3 ve F36b4 paftalıtopografik haritalar içerisinde ve 266000-273000 D ve 4572000-4576000 K (UTM-m) koordinatları arasında kalmaktadır (Şekil 1).

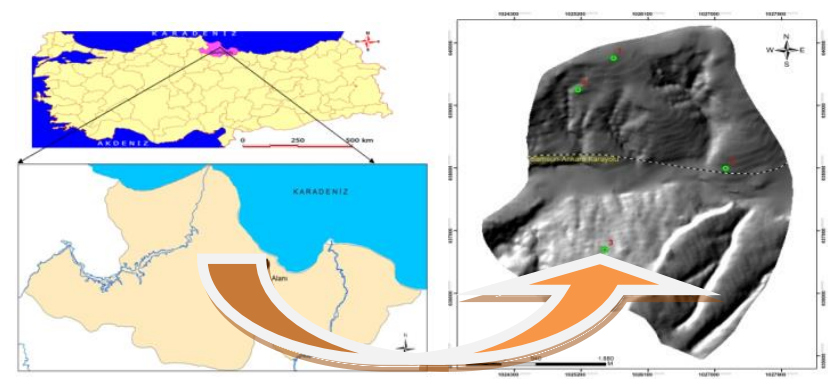

Şekil 1. Çalışma alanı lokasyon haritası 
Çalışma alanında marn ve bazalt iki farklı ana materyal üzerinde oluşmuş dört toprak profili incelenmiştir. Toprak profillerinden genetik horizon esasına göre morfolojik tanımlamalar yapılmış ve bozulmuş toprak örnekleri alınmıştır. Arazide toprakların morfolojik özelliklerinin incelenmesi amaciyla dikkate alınan kriterler, örneklemeler ve sinıflandırma için Soil Survey Staff (1993 ve 1999) kullanılmıştır. Alınan toprak örneklerinde;

Toprak örneklerinin bünye analizleri çöktürme metodu ile (Bouyoucos 1951), pH1:5 toprak-su süspansiyonunda cam elektrotlu pHmeter ve elekrtiksel iletkenlik 1:5 toprak-su süspansiyonunda ve organik madde Jackson'a göre (1958), $\mathrm{CaCO}_{3}$ Çağlar (1958), katyon değişim kapasitesi (KDK) US Salinity Lab. Staff' (1954) göre yapılmıştır. Atterberg limitleri (likit limit, plastik limit, büzülme limiti) Casagrande (1958) ve Head'de (1984) tanımlanan esaslar dahilinde Casagrande aleti ile yapılmıştır. Plastiklik indeksi; likit limitten plastik limitin çıkarılmasıyla birlenmiştir, Kil aktivitesi ise plastiklik indeksinin, kil yüzdesine oranlanmasıyla hesaplanmıştır (Skempton 1953). Elde edilen likit limit ve plastiklik indeksi değerlerinde Casagranda plastiklik kartı kullanılarak sınıflandırılması yapılmıştır.

XRD analizleri tüm toprak örnekleri kil minerallerin belirlenmesi amaciyla preparatlar hazırlanmış ve XRD eğrileri elde edilmiştir (Saka 1997). XRD çekimleri MTA Genel Müdürlüğü XRD laboratuvarında X-Işını difraktometer cihazı ile gerçekleşmiştir.

\section{Bulgular ve Tartışma}

\subsection{Topraklarm Morfolojik, Fiziksel, Kimyasal Özellikleri ve Siniflandirlmast}

Toprakların bazı fiziksel, kimyasal ve morfolojik özellikleri Çizelge 1'de verilmiştir. Typic Calciustert olarak sinıflandırılan Profil 1'e ait toprakların $\mathrm{pH}$ ' s1 8.06 ila 8.23 arasında olup, hafif alkalin reaksiyonludur. Toprakların kireç içerikleri yüzeyde $\% 16.3$ iken derinlikle artmakta ve $\% 47$ 'lere ulaşmaktadır. Bu durum toprak rengine de yansımakta olup yüzeyde value değerleri 3 iken derine doğru arttığ 1 dolaysıyla rengin açıldığı görülmektedir. Profil içerisindeki organik madde içerikleri \% 2.8 ila \% 0.3 arasında değişmektedir ve profil içerisinde yüzeyden derine doğru inildikçe azalma göstermektedir. Katyon değişim kapasiteleri 60.5-37.7 cmol.kg-1 arasında değişmektedir. Marn ana materyal üzerinde oluşmuş olan

Çizelge 1. Çalışma alanı topraklarının bazı fiziksel kimyasal ve morfolojik özellikleri

\begin{tabular}{|c|c|c|c|c|c|c|c|c|c|c|c|}
\hline \multirow[b]{2}{*}{ Horizon } & \multirow[b]{2}{*}{$\begin{array}{l}\text { Derinlik } \\
(\mathrm{cm})\end{array}$} & \multirow[b]{2}{*}{$\mathrm{pH}$} & \multirow[b]{2}{*}{$\begin{array}{c}\text { EC } \\
\left(\mathrm{dS} . \mathrm{m}^{-1}\right)\end{array}$} & \multirow[b]{2}{*}{$\begin{array}{c}\mathrm{CaCO}_{3} \\
(\%)\end{array}$} & \multirow[b]{2}{*}{$\begin{array}{l}\text { O.M } \\
(\%)\end{array}$} & \multicolumn{3}{|c|}{ Renk } & \multirow[b]{2}{*}{ Kivam } & \multirow[b]{2}{*}{ Strüktür } & \multirow[b]{2}{*}{$\begin{array}{c}\text { Özel } \\
\text { Görünüm }\end{array}$} \\
\hline & & & & & & $\begin{array}{c}\mathrm{KDK} \\
\left(\mathrm{cmol}^{\left.-\mathrm{kg}^{-1}\right)}\right.\end{array}$ & Kuru & Nemli & & & \\
\hline \multicolumn{12}{|c|}{ Profil 1- TypicCalciustert/ CalcaricVertisol } \\
\hline Ap & $0-19$ & 8.06 & 0.39 & 16.3 & 2.8 & 60.5 & $2.5 \mathrm{Y} 3 / 2$ & $2.5 \mathrm{Y} 3 / 2$ & $\mathrm{~h} \mathrm{st} \mathrm{pt}$ & $2 \operatorname{cgr}$ & çatlaklık \\
\hline Bss1 & $19-46$ & 8.33 & 0.41 & 20.9 & 1.1 & 47.7 & $2.5 \mathrm{Y} 4 / 2$ & $2.5 \mathrm{Y} 3 / 2$ & $\mathrm{~h} \mathrm{st} \mathrm{pt}$ & $2 \mathrm{msbk}$ & kayma yüzeyleri \\
\hline Bss2 & $46-76$ & 8.44 & 0.61 & 19.8 & 1.1 & 51.2 & $2.5 \mathrm{Y} 4 / 2$ & $2.5 \mathrm{Y} 4 / 3$ & h st pt & $3 \mathrm{msbk}$ & kayma yüzeyleri \\
\hline $2 \mathrm{Ck}$ & $76+$ & 8.23 & 1.91 & 47.0 & 0.3 & 37.7 & $2.5 Y 5 / 6$ & 2.5 Y 5/6 & h st pt & $\mathrm{m}$ & kireçmislleri \\
\hline \multicolumn{12}{|c|}{ Profil 2-CalcicHaplustert/CalcaricVertisol } \\
\hline Ap & $0-16$ & 7.98 & 0.29 & 7.7 & 4.5 & 67.8 & $2.5 \mathrm{Y} 3 / 2$ & $2.5 \mathrm{Y} 3 / 2$ & h st pt & $3 \mathrm{mgr}$ & \\
\hline Bss & $16-58$ & 8.22 & 0.33 & 13.7 & 1.4 & 62.8 & $2.5 \mathrm{Y} 4 / 2$ & $2.5 \mathrm{Y} 3 / 2$ & h st pt & $2 \mathrm{sbk}$ & kayma yüzeyleri \\
\hline $\mathrm{BC}$ & $58-103$ & 8.34 & 0.36 & 14.4 & 0.9 & 56.4 & $2.5 \mathrm{Y} 4 / 4$ & $2.5 \mathrm{Y} 4 / 3$ & h st pt & sbk ve m & kayma yüzeyleri \\
\hline $\mathrm{Ck}$ & $103+$ & 8.35 & 0.53 & 22.4 & 0.1 & 52.9 & $2.5 \mathrm{Y} 6 / 6$ & $2.5 Y 5 / 6$ & h st pt & $\mathrm{m}$ & kireçmislleri \\
\hline \multicolumn{12}{|c|}{ Profil 3-EnticHaplustert/ HaplicVertisol } \\
\hline A & $0-25$ & 8.08 & 0.41 & 12.8 & 1.3 & 47.9 & $2.5 \mathrm{Y} 5 / 4$ & $2.5 \mathrm{Y} 4 / 4$ & h st pt & $3 m g r$ & - \\
\hline Bss & $25-57$ & 7.76 & 2.44 & 19.2 & 0.2 & 41.8 & $2.5 Y 6 / 6$ & $2.5 Y 5 / 6$ & h st pt & $2 \mathrm{msbk}$ & kayma yüzeyleri \\
\hline $\mathrm{C} 1$ & $57-85$ & 7.77 & 3.31 & 18.6 & 0.1 & 39.7 & $2.5 Y 6 / 4$ & $2.5 Y 5 / 6$ & h st pt & $\operatorname{sg}$ & - \\
\hline $\mathrm{C} 2 \mathrm{r}$ & $85+$ & 7.82 & 3.67 & 20.3 & 0.2 & 41.1 & $2.5 \mathrm{Y} 6 / 4$ & $2.5 Y 5 / 4$ & $\mathrm{~h} \mathrm{st} \mathrm{pt}$ & $\mathrm{m}$ & - \\
\hline \multicolumn{12}{|c|}{ Profil 4-ChromicHaplustert/ChromicVertisol } \\
\hline Ap & $0-24$ & 7.96 & 0.59 & 12.7 & 2.4 & 57.9 & $2.5 \mathrm{Y} 4 / 3$ & $2.5 \mathrm{Y} 4 / 4$ & h st pt & $3 \mathrm{mgr}$ & \\
\hline Bss & $24-45$ & 8.11 & 0.63 & 16.1 & 1.3 & 53.1 & $2.5 Y 4 / 3$ & $2.5 \mathrm{Y} 5 / 3$ & h st pt & $2 \mathrm{msbk}$ & kayma yüzeyleri \\
\hline BC1 & $45-79$ & 8.21 & 0.82 & 21.0 & 0.5 & 51.4 & $2.5 \mathrm{Y} 6 / 4$ & $2.5 Y 5 / 6$ & h st pt & $2 \mathrm{msbk}$ & \\
\hline $\mathrm{BC} 2$ & $79-110$ & 8.10 & 1.59 & 21.5 & 0.3 & 41.1 & $2.5 \mathrm{Y} 6 / 3$ & $2.5 Y 5 / 3$ & h st pt & $\mathrm{m}$ & \\
\hline $\mathrm{Cg}$ & $110+$ & 8.05 & 1.73 & 25.4 & 0.2 & 41.4 & $2.5 \mathrm{Y} 6 / 4$ & $2.5 Y 5 / 4$ & $\mathrm{~h} \mathrm{st} \mathrm{pt}$ & $\mathrm{m}$ & gleyleşme \\
\hline
\end{tabular}

Strüktür: 1 = zayıf; 2 = orta; $3=$ kuvvetli; $\mathrm{sg}=$ tek dane; $\mathrm{m}=$ masif; $\mathrm{vf}=$ çok ince; $\mathrm{f}=$ ince; $\mathrm{m}=$ orta; $\mathrm{c}=$ kaba; gr= granüler; $\mathrm{pr}=$ prizmatik; abk = köşeli blok; sbk = yarıköşeli blok. Kıvam : (Kuru) lo = gevşek; so = yumuşak; sh = hafif sert; h = sert; (Islak) so = yapışkan değil; ss = hafif yapışkan; st= yapışkan; po = plastik değil; ps = hafif plastik; $\mathrm{pt}=$ plastik

Calcic Haplustert (Profil 2) toprakların pH's1 7.98 ila 8.35 arasinda olup, hafif alkalin reaksiyonludur. Profil içerisindeki katyon değişim kapasiteleri 67.8-52.9 cmol. $\mathrm{kg}^{-1}$ arasında, organik madde içerikleri ise $\% 4.5$ ila \% 0.1 arasında değișmekte olup profil içerisinde yüzeyden derine doğru inildikçe azalma göstermektedir. Profil 3 ile temsil edilen Entic Haplustert topraklar diğer topraklarda olduğu gibi hafif alkalin reaksiyonludur. 
Fakat profil içerisinde kalsifikayon olayı belirlenmemiştir. Kireç içeriği profil içerisinde çok fazla değişkenlik göstermemekte bu durum renk değişiminde de fazla fark yaratmamaktadır. Chromic Haplustert ait toprakları diğer vertisollerde olduğu gibi şişme özelliğindeki killerin miktarı çok fazla (profil boyunca $\% 50$ ve daha fazla), derin çatlaklara sahip olmaları ve profil içerisinde yer yer kayma yüzeylerin görülmektedir. Topraklarının $\mathrm{pH}^{\prime}$ s1 7.96 ila 8.21 arasında olup, hafif alkalin reaksiyonludur. Organik maddenin ise yüzeyde \% 2.4 olup derinlere doğru azaldığ 1 belirlenmiştir. Katyon değişim kapasiteleri 41.1-57.9 cmol. $\mathrm{kg}^{-1}$ arasında değişmektedir. 4 profilde de tuzluluk problemleri bulunmamaktadır.

Çalışma alanı toprakları arazide yapılan morfolojik

\subsection{Kil Minerolojisi}

Killi toprakların jeoteknik karakteristikleri, onların minerolojik kompozisyonlarını özelliklede kil minerolojilerini etkilemektedir. Sıkışabilirlik, plastiklik, şişme potansiyeli gibi indeks özellikler yüzde olarak simektit kil minerali miktarları artıkça artış göstermektedir. Çalışma alanındaki dağılım gösteren çalışmaların yanı sıra laboratuar analiz sonuçları da dikkate alınarak Toprak Taksonomisine (Soil Taxonomy, 1999) göre 1 ordo, 1 altordo, 2 büyük grup ve 4 alt grup içerisine yerleştirilmiştir (Çizelge 2). Araştırma alanında yer alan toprakların rutubet rejimleri ustic ve sicaklık rejimleri ise mesictir. Toprakların toprak taksonomisine göre sınıflandırılması, toprakların pedogenetik özellikleri ile üst tanı horizonları (epipedon) ve bunların altında bulunan yüzey altı tanı horizonları ve özelliklerine göre yapılmıştır. Toprakların oluşum süreci sonrasında oluşan bazı yüzey üstü ve yüzey altı tanı horizonları saptanmış ve hepsi Vertisol ordosu içerisinde tanımlanmıştır. FAO/ISRIC (2006) göre ise yine Vertisol' dür.

farklı toprakların minerolojik bileşimlerini belirleyebilmek amaciyla yüzey ve derinden toplam örnek üzerinde X-1̧̧ııları çözümlemeleri (XRD) yapılmıştır (Şekil 2). Çalışma alanında hakim kil minerali simektit grubu 2:1 tipi şişen kil minerallerinden montmorillonit olup ikinci ve üçüncü derecede yaygın olarak gözlenen kil mineralleri ise nontronit ve kaolinit olarak belirlenmiştir.

Çizelge 2. Çalışma alanı toprak serilerinin Toprak Taksonomisine (Soil Taxonomy, 1999) ve FAO-WRB (2006) göre sinıflandırması

\begin{tabular}{c|c|c|c|l}
\hline \multicolumn{4}{c}{ Toprak Taksonomisi (1999) } & \multirow{2}{*}{ FAO-WRB (2014) } \\
\hline \multirow{3}{*}{ Ordo } & Alt Ordo & Büyük Grup & Alt Grup & \\
\hline \multirow{3}{*}{ Vertisol } & \multirow{3}{*}{ Ustert } & \multirow{2}{*}{ Haplustert } & CalcicHaplustert & CalcaricVertisol \\
\cline { 3 - 4 } & & & EnticHaplustert & HaplicVertisol \\
\cline { 3 - 4 } & & Calciustert & ChromicHaplustert & ChromicVertisol \\
\cline { 3 - 4 } & & &
\end{tabular}

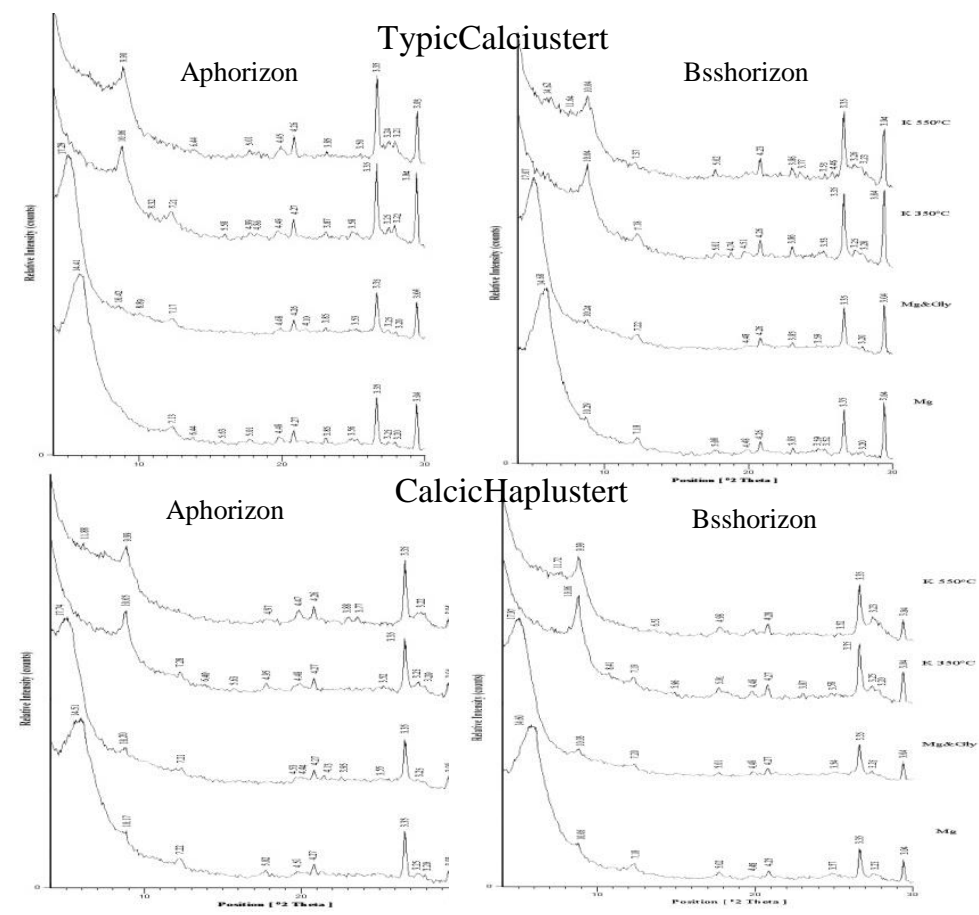

Şekil 2. Typic Calciustert ve Calcic Haplustert topraklara ait yüzey ve yüzey altı horizonlarının kil pikleri 


\subsection{Toprakların Klvam İndeks Özellikleri}

Kivam limitleri, ince taneli toprakların sınıflandırılmasında, şişme ve aktivite özelliklerinin belirlenmesinde, minerolojik özellikleri hakkında fikir vermesi açısından önemli parametreler olarak değerlendirilmektedir. $\mathrm{Bu}$ nedenle bu çalıșma kapsamında 17 adet toprak örneği üzerinde kıvam limitleri ve plastisite indeks değerleri belirlenerek değerlendirilmiştir. Elde edilen sonuçlar toplu olarak çizelge 3'de sunulmuştur. Toprakların likit limit ve plastiklik indeksi değerleri sırasıyla (\%53-70) ve (\%2740) arasında değişim göstermektedir. Tane büyüklük dağılımı analiz sonuçları elde edilen kum silt ve kil tane boyut dağılımı çizelge 3'de verilmiştir. Çizelgede de ifade edildiği gibi tane büyüklük dağılımın tamamını killi tekstür oluşturmaktadır.

Çizelge 3.Çalışma topraklarına ait tane büyüklük dağılımı ve kıvam indeks değerleri

\begin{tabular}{|c|c|c|c|c|c|c|c|c|c|c|c|c|c|}
\hline & \multirow{2}{*}{$\begin{array}{l}\text { Horizon } \\
\text { Derinlik }\end{array}$} & & \multicolumn{4}{|c|}{ Bünye (\%) } & \multicolumn{4}{|c|}{ Atterberg limitleri (\%) } & \multirow[b]{2}{*}{ USCH } & \multirow[b]{2}{*}{ Şişme } & \multirow[b]{2}{*}{ Plastiklik } \\
\hline & & & $\mathrm{C}$ & $\mathrm{Si}$ & $\mathrm{S}$ & Sinıf & LL & PL & Ip & A & & & \\
\hline \multirow{4}{*}{$\begin{array}{c}\text { Typic } \\
\text { Calciustert }\end{array}$} & $\mathrm{Ap}$ & $0-19$ & 75 & 18 & 7 & $\mathrm{C}$ & 65 & 32 & 33 & 0.44 & $\mathrm{CH}$ & yüksek & yüksek \\
\hline & Bss1 & $19-46$ & 68 & 18 & 14 & $\mathrm{C}$ & 60 & 33 & 27 & 0.40 & $\mathrm{CH}$ & orta & yüksek \\
\hline & Bss2 & $46-76$ & 73 & 23 & 5 & $\mathrm{C}$ & 58 & 30 & 28 & 0.39 & $\mathrm{CH}$ & orta & yüksek \\
\hline & $2 \mathrm{Ck}$ & $76+$ & 56 & 24 & 20 & $\mathrm{C}$ & 53 & 25 & 28 & 0.50 & $\mathrm{CH}$ & orta & yüksek \\
\hline \multirow{4}{*}{$\begin{array}{c}\text { Calcic } \\
\text { Haplustert }\end{array}$} & Ap & $0-16$ & 66 & 24 & 11 & $\mathrm{C}$ & 69 & 36 & 33 & 0.50 & $\mathrm{CH}$ & yüksek & yüksek \\
\hline & Bss & $16-58$ & 70 & 18 & 12 & $\mathrm{C}$ & 68 & 34 & 34 & 0.49 & $\mathrm{CH}$ & yüksek & yüksek \\
\hline & $\mathrm{BC}$ & $58-103$ & 78 & 18 & 4 & $\mathrm{C}$ & 70 & 32 & 38 & 0.49 & $\mathrm{CH}$ & yüksek & Çok yüksek \\
\hline & $\mathrm{Ck}$ & $103+$ & 59 & 27 & 14 & $\mathrm{C}$ & 61 & 29 & 32 & 0.55 & $\mathrm{CH}$ & orta & yüksek \\
\hline \multirow{4}{*}{$\begin{array}{c}\text { Entic } \\
\text { Haplustert }\end{array}$} & A & $0-25$ & 72 & 27 & 1 & $\mathrm{C}$ & 64 & 28 & 36 & 0.50 & $\mathrm{CH}$ & yüksek & yüksek \\
\hline & Bss & $25-57$ & 74 & 20 & 6 & $\mathrm{C}$ & 58 & 26 & 32 & 0.43 & $\mathrm{CH}$ & Orta & yüksek \\
\hline & $\mathrm{C} 1$ & $57-85$ & 64 & 27 & 9 & $\mathrm{C}$ & 58 & 26 & 32 & 0.50 & $\mathrm{CH}$ & Orta & yüksek \\
\hline & $\mathrm{C} 2 \mathrm{r}$ & $85+$ & 53 & 31 & 16 & $\mathrm{C}$ & 53 & 26 & 27 & 0.51 & $\mathrm{CH}$ & Orta & yüksek \\
\hline \multirow{5}{*}{$\begin{array}{l}\text { Chromic } \\
\text { Haplustert }\end{array}$} & Ap & $0-24$ & 61 & 23 & 17 & $\mathrm{C}$ & 65 & 30 & 35 & 0.58 & $\mathrm{CH}$ & yüksek & yüksek \\
\hline & Bss & $24-45$ & 58 & 25 & 17 & $\mathrm{C}$ & 66 & 28 & 38 & 0.65 & $\mathrm{CH}$ & yüksek & yüksek \\
\hline & $\mathrm{BC} 1$ & $45-79$ & 72 & 27 & 1 & $\mathrm{C}$ & 65 & 25 & 40 & 0.55 & $\mathrm{CH}$ & yüksek & yüksek \\
\hline & $\mathrm{BC} 2$ & $79-110$ & 68 & 24 & 7 & $\mathrm{C}$ & 63 & 26 & 37 & 0.54 & $\mathrm{CH}$ & yüksek & yüksek \\
\hline & $\mathrm{Cg}$ & $110+$ & 70 & 29 & 1 & $\mathrm{C}$ & 62 & 25 & 37 & 0.53 & $\mathrm{CH}$ & yüksek & yüksek \\
\hline
\end{tabular}

C: Kil, S: Sand, Si: Silt, LL: Likit Limit, PL: Plastik Limit, Ip: Plastiklilik İndeksi, USCH: Birleştirilmiş toprak sınıflama sistemi

\subsection{Kil Minerallerinin Klvam İndeks Özellikler Ile Olan Illişkisi}

Kivam limitleri, ince taneli zeminlerin sınıflandırılmasında, aktivite, şişme ve kil tipi gibi durumlarının tahmin edilmesinde kullanılan temel parametrelerdir. Likit limit ve plastik limit arasındaki ilişki iki limit arasındaki fark olarak tanımlanan plastiklik indeksi dikkate alınarak tanımlanır ve toprağın plastiklik gösterdiği nem içeriğini temsil eder. Likit limite karşılık gelen plastiklik indeksi plastiklik kartı olarak ifade edilir (Wagner 1957). Plastiklik kartı üzerinde bulunan A çizgisi likit limiti \% 20 nem içeriğinden keser ve eğimi 0.73 dür. Plastisite kartı üzerinde işaretli bulunan toprakların genel mühendislik durumları hakkında fikir vermektedir.

Vertisol ordosu içerisinde tanımlanan (Calci
Haplustert Entic Haplustert, Chromic Haplustert, Typic Calciustert) toprak örnekleri vertisol toprağın önemli bir kriteri olan yüksek kil içeriğini karşılayacak şekilde (\%53-78) tamamen kil bünye sahip olmakta ve likit limit ve plastiklik indeksi değerleri sırasıyla (\%53-70) ve (\%27-40) arasında değişim göstermektedir. Profil ve horizonlardaki bu değișimin nedeni örneklerin içerdiği kil oranı, kil mineralinin tipi ve fraksiyon içindeki dağılımlarıdır. Profilinde en yüksek (\%78) kil içeriğine sahip olan Calci Haplustert (\%70) ile de en yüksek likit limit değeri vererek çok yüksek plastiklik göstermiştir. Entic Haplustert alt grubunda ise en düşük kil içeriğinde (\%53) yine en düşük (\%53) likit limit değerini alarak yüksek plastiklik gösterdiği tespit edilmiștir. Çalıştığımız Vertisol topraklar içerisinde çok uç değerlere rastlanmaması hem profillerdeki \% kil değerlerini hem de sahip oldukları kil mineral tiplerinin 
aynı olmasından kaynaklanmaktadır. Çalışma alanı toprakları plastisite kartı yani likit limit ve plastisite indeksi değerleri kullanılarak örnekler kart üzerine yerleştirilmiş ve birleştirilmiş toprak sınıflama sistemine göre sinıflandırıldığında ise örneklerin sahip olduğu bu indeks değerlerinin plastisite kartındaki dağılımları Şekil 3'de verilmiştir. Şekil 3 üzerinde de görüldüğü üzere, zemin özellikleri bakımından tüm toprak profillerinde Birleşik sınıflama Sistemine göre $(\mathrm{CH})$ yüksek plastisiteli inorganik killer sonucuna ulaşılmıştır. Boyraz ve Sarı (2012) yaptığı çalışmasında topraklarını Entisol, İnceptisol ve Ventisol Ordoları içerisinde tanımlamış genelde kil tekstüre sahip olan örneklerde likil limit ve plastik limit değerlerini (\% 84-19) ve (\% 42-16) olarak belirlemiştir. Profilde ve horizonlarda meydana gelen bu farklılığı kil oranları ve mineral tiplerindeki farklılık olarak açıklamıştır ve (CL) düşük plastisiteli , $(\mathrm{CH})$ yüksek plastisiteli killer olarak sınıflandırmıştır. Yılmaz (2009) da Türkiye de beş aluviyal depozitten aldığ 1 killi toprak örneklerinde yaptığı çalışmada; örneklerini birleştirilmiş toprak sınıflama sistemine göre sinıflamış ve $\% 50$ sini $\mathrm{CH}$ (inorganik kil, yüksek plastisite), \% 50 sini ise CL (inorganik kil, düşük plastisite) olarak tanımlamıştır. Ayrıca toprak örneklerinde gerçekleştirilen plastik ve likit limit analizleri ile kil tipi hakkında da destekleyici veri elde edilebilinmektedir (Atterberg, 1912; Casagrande, 1934; Campbell, 1911). Çalışma alanı topraklarının \% 100'ünin likit limit değeri \%50 nin üzerinde pilastiklik insinin ise \% $76^{\prime}$ s1 $\% 30$ ün üzerindedir. Kil düzeyi \% 40'ın üzerinde olan örnekte yapılan plastik ve likit limit analiz sonuçları plastiklik indisi 30'un üzerinde, likit limit 50'nin üzerinde saptanırsa söz konusu toprağın hakim kil mineralininin smektit grubu kil minerali olduğu söylenebilir (Kapur ve Akça, 2015). Şekil 3'de görüldüğü gibi XRD sonuçlarının da ortaya koyduğu şekilde toprak profil örneklerimizin tamamının plastisite kartı üzerinde yoğunlaştığ 1 bölge, hakim kil mineralinin smektit gurubu kil minerali olduğunu işaret eden bölge olarak görülmektedir. Ayrıca Gougazeh ve Al-Shabatat (2013) alüvyal ve heyelanlı toprak materyallerini minerolojik ve fiziksel özelliklerini inceleyerek alüvyal materyalin likit limit değerini \%20-40, plastiklik indeksi değerinin ise \% 7.3-16.3 arasinda, heyelanlı materyalin ise sırasıly likit limit ve plastiklik indeksi değerlerinin \%28-58 ile \%12-43 arasında değiştiğini bularak XRD analiz sonuçlarına göre de bu durumu destekler şekilde hakim kil mineralinin heyelanlı materyalde smektit grubu kil minerali olduğunu tespit etmişlerdir.

Plastisite indisinin kil \%'sine oranlanmasıyla elde edilen aktivite parametreleri, topraktaki kil miktarı ile kil mineral tipinin toprağın mühendislik özellikleri üzerine olan etkisinin ayrımlılığını yansıtır (Altınbaş ve Zorba, 1990). Altınbaş ve Zorba (1990), toprakların mühendislik özellikleri üzerine yaptıkları araştırmada aktivite ile plastik limit arasında pozitif, kil arasında negatif ve kum arasında ise pozitif ilişkiler saptamışlardır. Çalışma alanı aktivite değerleri ise Skempton (1953); Gillot (1987)'e göre sinıflandırması yapılmış ve bu sınıflamaya göre değerler vertisolordosu içerindeki tüm alt ordolarda 0.39-0.65 arasında değişim göstererek; aktif olmayan killer olarak ifade edilmiştir. $\mathrm{Bu}$ durum kil yüzdesi fazla ve hakim kil mineralinin smektit grubu kil minerali olmasına karşın; yine smektit grubu bir kil minerali olan nontronit kil mineralinin varlı̆ğından kaynaklanmaktadır. Bu mineral smektit grubu olmasına karşın su tutma ve diğer özellikler bakımından montmorillonit gibi özellikler göstermemektedir (Mitchell, 1993). A. M.A. Esraa (2011) yılında Irak Th1-Qra Üniversitesi topraklarında yaptığı çalışmasında toprakların fiziksel ve minerolojik özelliklerini incelemiş ve yaygın kil mineralinin montmorillonit olarak belirlemiş, bunu illit ve kaolinit olduğunu saptamıştır. Aktivite değerlerini ise ortalama da (\%80) aktif olmayan ve (\%20) normal aktif killer olarak belirlemiştir. Toprakların şişme potansiyelleri de aktiviteleri ile yakından ilişki göstermektedir.

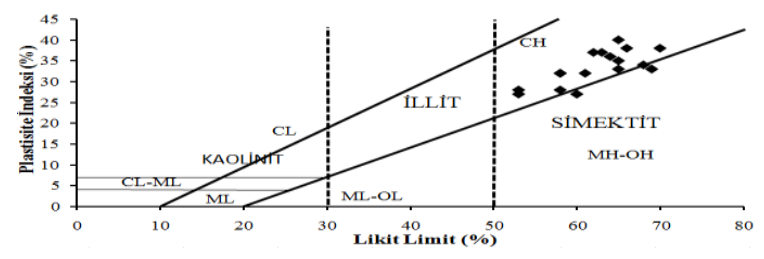

Şekil 3. Toprak örneklerinin plastisite kartı üzerindeki dağılımları ve Atterberg plastik ve likit limit değerleri ile kil minerolojisi ilişkisi

Toprak örneklerin Van Der Merve (1964)'ün şişme potansiyeli sınıflama abağı üzerindeki dağılımları şekil 4 ve şekil 5'de verilmiştir.

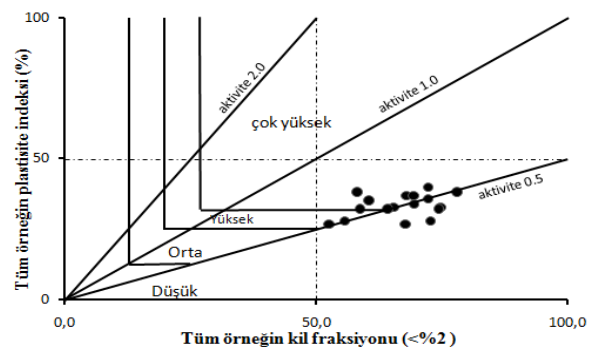

Şekil 4. toprak örneklerinin VAN DER MERVE (1964)'ün şişme potansiyeli abağı üzerindeki dağılımları ( van der Merwe 1964).

Her iki şekilde de görüldüğü gibi örneklerin yaklaşık olarak tamamı orta ve yüksek şişme potansiyeli bölgelerinde yer almaktadır. O'Neill ve Poormoayed şişme potansiyelinin belirlendiği sınıflandırma da (Çizelge 3) ise Vertisol Ordosunda yer alan; Typic Calciustert ve Entic Haplustertlerin yüzey horizonu 
hariç diğer tüm horizonlarında ve Calcic Haplustert in sadece (Ck) horizonunda orta şişme potansiyeline, geri kalan tamamı ve Chromic Haplustert alt grubunun yine tüm horizonlarında yüksek şişme potansiyeli tespit edilmiştir. Karacan ve Aslan (2001);Sivas-Şarkışla Kanak Barajı inşaatında kullanılacak olan geçirimsiz toprak malzemelerin minerolojik ve fiziksel incelemeleri sonucu egemen olan kil mineralinin simektit olduğunu ve örneklerin yaklaşık olarak tamamının düşük-orta şişme potaniyeline sahip olduğunu tespit etmişlerdir.

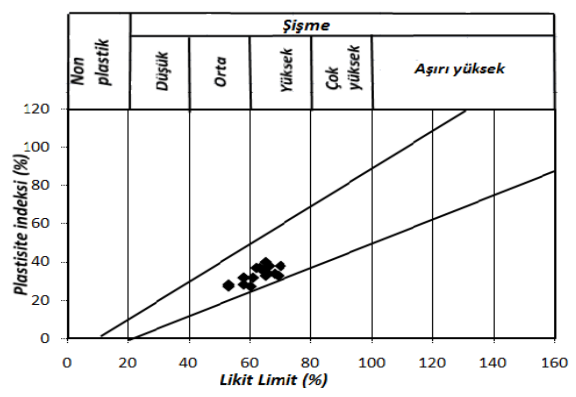

Şekil 5. toprak örneklerinin Dakshanam ve Raman (1973) ün şişme potansiyeli abağı üzerindeki dağılımı.

Killerin jeoteknik karakteristikleri; onların minerolojik yapılarıyla özelikle de kil kompozisyonları ile ilişkili olduğunu söylemek mümkündür. Örneğin killerin simektit yüzdeleri arttıkça plastisite ve şişme potansiyelleri de artmaktadır (Yılmaz ve Karacan, 1997)

\section{Sonuç}

Kil minerali tiplerinin toprak bileşimindeki içeriği, kil minerallerinin toprak özelliklerinin belirlemesi açısından önemlidir. Kil minerali, kil fraksiyonun da yüksek düzeyde bulunsa dahi, eğer topraktaki kil fraksiyonu yüzdesi çok düşükse bu kil mineralinin toprağın fiziksel ve kimyasal özellikleri üzerine etkisini çok da yansıtmayabilir. Kil minerallerinin kil fraksiyonun dan ziyade toprak bileşimindeki miktarı bitki yetiştiriciliği ve zemin mühendisliği açısından önem taşımaktadır. Smektitin Vertisol (Calci Haplustert, Entic Haplustert, Chromic Haplustert, Typic Calciustert) ordolarında fazla oranda bulunması, yapılan zemin mekaniği analiz sonuçları ile de uyumlu bulunmuştur. Samsun bölgesinde yer alan Vertisol Ordoları üzerinde yapılan bu çalışmada $\% \quad 60$ in üzerinde kil bulunduran içerdikleri kil mineraller tipi nedeniyle kuruma sonrasında toprak yüzeyinde büzülme sonucu ortaya çıkan çatlaklara rastlanması ve genişleyebilen kil minerallerini içeren topraklar olduğu için kurak dönemlerde büzülme sonrası, toprak yüzeyinden başlayarak profil derinliğinde devam eden geniş ve derin çatlakların toprakta oluşması Vertik özellikleri sağlayan simektik grubu kil minerallerin hakim durumda olması ve bu durumun diğer analizler ile desteklenmesi, vertisol toprak özellikleri ile zemin mekanik analiz sonuçlarının tutarlılığını ortaya koymaktadır. Yapılan çalışmada bu toprakların birleştirilmiş toprak sınıfının $\mathrm{CH}$ (Yüksek likit limitli kil) grubunda yer alması yüksek olasılıkla ortamdaki smektitin yüksekliğinden kaynaklanmaktadır. Topraklarının yüksek derecede şişme-büzülme zararına sahip olduğu ve yüksek plastiklik gösterdiği de tespit edilmiştir. Simektit gurubu kil minerallerini içeren toprakların zemin açısından sorunlu olabileceği, bu açıdan gerekli kültürel önlemlerin alınması ve zemin mekaniği araştırmalarının daha detaylandırılması gerektiği öneri olarak düşünülebilmektedir.

\section{Kaynaklar}

Abdulaemma Mandhour Alfatlawi, E., 2011. Swelling Potential and Mineralogy Of Th1-Qar University Soil. Journal of Thi-Qar University. 1(7): 1-15 pp.

Ahmad, N., 1983. Vertisols. In Wilding, L.P.,Smeck, N.E. \& Hall, G.F. (Eds), Pedogenesis and Soil Taxonomy, The Soil Orders. Developments in Soil Science. Amsterdam, Oxford, New York, Tokyo, IIB, Elsevier, pp. 91-123.

Altınbaş, Ü. ve Zorba, M., 1990. Yamanlar Dağı Yöresi (İzmir) Kireçsiz Kahverengi Büyük Toprak Grubunun Zemin Mekaniği Yönünden Kimi Mühendislik Özellikleri Üzerine Araştırmalar, Ege Üniversitesi Ziraat Fakültesi Dergisi Cilt:26, Sayı:1, Bornova.

Atterberg, A., 1911. Dieplastizitat der tone, Intern Mitteil Bodenkunde, 1, 4-37.

Atterberg, A., 1912. Diemecanische Bodenenal yeseunddie klassifikation der mineralboden sechwedens. Int. Mitt. Bodenk., 2, 312-342.

Bouyoucous, G.J., 1951. A Recalibration of Hidrometer for Making Mechanical Analysis of Soils. Agronomy Journal. 43:9

Boyraz, D., Sarı, H., (2012), Tekirdağ Değirmenalt1-Muratlı Kavşağı Çevre Yolunu Oluşturan Katenadaki Toprakların Fiziksel ve Zemin Özelliklerinin Değerlendirilmesi. Tekirdağ Ziraat Fakültesi Dergisi. 9(3), 68-78.

Campbell, D.J., 1911. Liquid and plasticlimits. In 'Soil analaysis - physical methods' (Eds KA Smith, CE Mullins) Dekker Inc., 367-398 New York.

Canbolat, M.Y, Barik, K., Özgül, M., 1999. Erzurum Yöresinde Farklı Ana Materyaller Üzerinde Oluşmuş Üç Toprak Profilinin Kıvam Limitleri ve Şişme-Büzülme Karakteristikleri. Atatürk Üniv. Ziraat Fak. Derg. 30 (2): 121-129.

Canbolat, M.Y., Öztaş, T., Akgül,M., Barik, K., 1998. Erzurum Daphan Ovası Topraklarının Mekaniksel Özellikleri. Doğu Anadolu Tarım Kongresi, Erzurum.

Casagrande, A., 1958. Classification and Identifications of Soils Trans. Am. Soc. Civil Eng. 113:901-930

Casagrende, A., 1934. Diearaometer-methotezur Bestimmum der Kornverteilungvon Boden und Anderen Materialen. Springer J.

Çağlar, K.Ö., 1958. Toprak İlmi Atatürk Üniversitesi Ziraat Fakültesi yayınları. No:10 Ankara

De Jong, E., D.F. Acton, H. B. Ststone house, 1990. Estimating the Atterberg Limits of Southern Saskatchewan Soils From Texture and Carbon Contents. Can. J. Soil Sci., 70: 543- 554.

Dumbleton, M. J., West, G., 1966. Some Factors Affecting 
The Relation Between The Clay Minerals in Soils and Their Plasticity. 6, 179.

FAO-WRB., 2014. World Referances Base For Soil Resources World Soil Rep., No, 106. Rome, 203p.

Gillot E.J:, 1987, Clay in Engineering Geology. Elsevier, Amsterdam, 468p.

Gougazeh, M., Al-Shabatat, A., 2013. Geological and Geotecnical Properties of Soil Materials at Tannur Dam, Wadi Al Saha, South Jordan. Journal of Taibah University for Science. 216-222

Grim, R.E., 1949, Minerological composition in relation to the properties of certain soils: Geotechnique, 1, 139-147

Head, K.H., 1984. Manual of Soil Laboratory Testing Volume I. Soil Classification and Compaction Tests. Ele International Ltd. Patech Press, London.

Jakson, M.L. 1958. Soil Chemical Analysis. Prentice Hall Inc., Englewood Cliffs, N.J.

Kapur, S., Akça, E., 2015. TC. Gıda Tarım ve Hayvancılık Bakanlığı Tarım Reformu Genel Müdürlüğü. Toprak Etüd Haritalama El Kitab1. Minerolojik ve Mikromorfolojik Özellikler. 210-223.

Karacan, E., Arslan, A.T., 2001. Kanak Barajı (Sivas-Şarkışla) İnşaatında Kullanılacak Olan Geçirimsiz Toprak Malzemelerin Minerolojisi ve Jeoteknik Özellikleri. Yer Bilimleri Dergisi, C.14, S. 15-26

Mitchell, J.K., 1993. Fundamentals of Soil Behaviour, 2nd ed. Wiley, New York.

Nagaraj, T.S., Jayadeva M.S., 1983. Critical reapprasial of plasticity index of soils, J. Geotech. Eng. Div. ASCE, 109(7): 994-1000

Saka, A.H., 1997. Mineralojik analizler. x-1şınları toz kırınım yöntemlerinin temel prensipleri ve laboratuar şartlarının standardizasyonu. MTA Min. Araş. Koor. s, 235. Ankara.
Seed, H.B., Woodward, R.J., Lundgren,R., 1962. Prediction of swelling potential for compacted clays: Jour. Soil Mech. and Found. Division, ASCE 88: 57-88.

Sivapullah, P.V., and Sridharan, A., 1985. Liquid Limid Of Soil Mixtures, Geotech, Testing.,8(3): 11-116.

Skempton, A.W., 1953. Thecolloidal activity of clays. Proc. 3rd Intl. Conf. Soil Mechs. Found. Eng.,Zurich, I, 57-61

Soil Survey Staff. 1983. USDA National Handbook 20013, Washington D.C

Soil Survey Staff, 1999. Soil Taxonomy. A Basic of Soil Classification for Making and Interpreting Soil Survey. U.S.D.A Handbook No: 436, Washington D.C.

SSSA, 1997. Glossary of soil science terms. SSSA, Wisconsin.

Tan, T.S.,Goh, T.C., Kuranaretne, G.P., Lee, S.L., 1994. Shear strength of very soft clay-sand mixtures, Geotech, Testing.,J., 17(1): 27-37.

Terzaghi, K., and Peck, R.B., 1967, soil mechanics in engineering practice: new York, John Wiley and Sons, Inc., 729p.

US Salinity Laboratory Staff. 1954. Diagnosis and Improvement of Saline and Alkali Soils. Agri. Handbook. No:60, USDA.

Wagner, A.A., 1957. Theuse of the Unified Soil Classification System by the Bureau of Reclamation: Proceedings, 4th International Conference on Soil Mechanics and Foundation Engineering (London), Vol. 1, p. 125.

Wan Der Merwe, D.H., 1964. The prediction of heave from the plasticity index and percentage clay friction of soils. Civil Engineering in South Africa, 6(6): 103-106.

Y1lmaz, I., 2009. Swell Potantial and Shear Strength Estimation of Clays. Applied Clay Science. 46, 376-384.

Yilmaz, I., Karacan., E., 1997. Geotechnicalproperties ofalluvial soils: an example from south of Sivas (Turkey). IAEG, Bulletin of International Association of Engineering Geology, France No., 55. 